\title{
La judería nueva de Calatayud. Visión arqueológica
}

\author{
The Jewish aljama in Calatayud. An archaeological scope
}

\author{
José Luis Cebolla Berlanga*, Salvador Melguizo Aísa* \\ Francisco Javier Ruiz Ruiz*
}

\section{RESUMEN}

La aljama judía de Calatayud fue la más importante de Aragón inmediatamente por detrás de la de Zaragoza. La judería se hallaba emplazada intramuros en una zona de difícil orografía en la parte noroccidental de la ciudad. Aunque la judería ya había sido objeto de algunas intervenciones arqueológicas de carácter puntual, entre los años 2005 y 2008 hemos podido excavar tres solares contiguos $\left(2430 \mathrm{~m}^{2}\right)$ ubicados a escasos metros de la puerta de Toledo. Allí se ha podido documentar una densa trama urbana que urbanísticamente responde a una ampliación a extramuros de la ciudad. Su ocupación se inicia como muy temprano en torno a los primeros años del siglo XIV y su final claramente en el año 1362, siendo destruido durante el sitio de Calatayud en la Guerra de los dos Pedros. Los hallazgos de varios fragmentos de janukía en el interior de las viviendas excavadas, elementos únicamente utilizados por la comunidad hebrea, nos permiten plantear la realidad de una ampliación a extramuros del barrio judío de Burgimalaco a principios del siglo XIV.

Palabras clave: Calatayud, judería, urbanismo, Puerta de Toledo, hanukiyah.

\section{La judería de Calatayud}

Calatayud (Zaragoza) se ubica en las estribaciones meridionales de la sierra de Armantes, entre los barrancos de la Rúa o de Soria y el de las Pozas que desembocan en el río Jalón, que riega su rica huerta. Y siempre ha constituido un punto clave de las comunicaciones entre la Meseta y el valle del Ebro a través de las cuencas de los ríos Jalón y

\begin{abstract}
The Jewish aljama in Calatayud was the most important of Aragón, immediately behind that of Zaragoza. The Jewish quarter was located from historical sources inside the city walls, in an area of rough terrain in the northwestern part. Although the Jewish quarter had already been the subject of some archaeological research, between years 2005 and 2008, we were able to dig three contiguous places located a few meters from the old gate of Toledo. There has been documenting a dense urban weave that responds to an extension to outside the city. His occupation is initiated as early on the early fourteenth century and the end clearly in the year 1362, being destroyed during the siege of Calatayud in the War of the Two Peters. The findings of several ceramic fragments of Hanukiah candle oil lamps inside the houses excavated, items only used by the Jewish community, allow us to raise the reality of an extension to the outside of the Jewish quarter of Burgimalaco early fourteenth century.
\end{abstract}

Key words: Calatayud, Jewry, urbanism, Gate of Toledo, Hanukiah.

Henares, y entre la Meseta y el litoral mediterráneo a través de los ríos Jiloca y del Turia a partir de Teruel.

La ciudad medieval se hallaba protegida por un extenso complejo fortificado de origen islámico compuesto por cinco castillos, situados sobre las cumbres de otros tantos cerros, unidos entre sí por kilómetros de lienzos de muralla. Debido a su estratégica situación de

* Arqueólogo profesional 
cruce de caminos, se convirtió en el siglo XIV en uno de los principales centros mercantiles del reino de Aragón, además de centro financiero, manufacturero y dedicado a actividades agropecuarias. También tuvo una gran importancia estratégica dentro del sistema defensivo de la frontera Este de Aragón por su situación fronteriza con Castilla.

La presencia judía en Calatayud se remonta al período musulmán. Tras la conquista por Alfonso I (1120), se les permite permanecer en la población, convirtiéndose la comunidad de Calatayud entre los siglos XII y XV en una de las más importantes comunidades judías del reino de Aragón, inmediatamente por detrás de la de Zaragoza. Se hallaba emplazada intramuros, en una zona de difícil orografía en la parte noroccidental de la ciudad, a los pies del hoy denominado castillo de Doña Martina, en un espacio que queda completamente cerrado por la muralla que unía a éste con los castillos de Torre Mocha y de la Peña.
La judería bilbilitana (fig. 1) era atravesada por el barranco de las Pozas, hoy rellenado y cubierto por la calle Ronda Puente Seco. El recinto de la judería contó inicialmente con cuatro vías de acceso. La principal era la puerta de San Andrés, situada al este, en el comienzo de la actual cuesta de Santa Ana, mientras que al noroeste se situaba el postigo de Torre Mocha, abierto en 1264 con autorización de Jaime I. La puerta de Toledo se abría en la muralla sur y la puerta de la Furiega en la muralla oeste.

La muralla meridional partía del montículo del castillo de la Peña (hoy Santuario de la Virgen de la Peña), discurría por la actual calle de la Escalera de la Peña, atravesaba el barranco de las Pozas y giraba barranco abajo hacia la puerta de Terrer. La puerta de Toledo se emplazaba a la altura del denominado Puente Seco que salvaba el cauce del barranco, antes del giro hacia la puerta de Terrer (A. López, 2003:61-62).

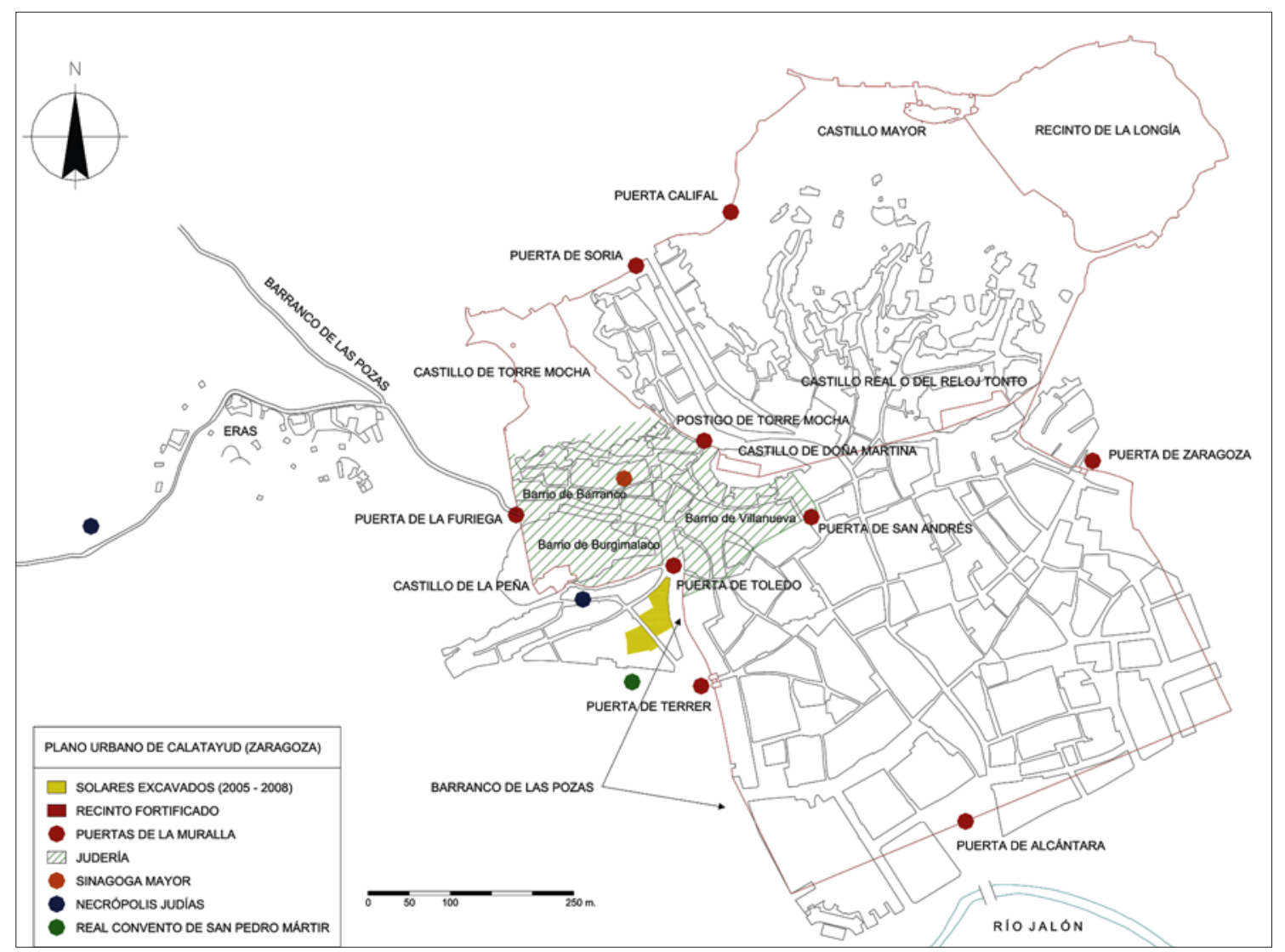

Figura 1. plano de Calatayud con indicación de la judería, fortificaciones y el área excavada. 
A partir de los estudios realizados por $F$. Cantera (1953:363-364), la necrópolis judía se ha venido ubicando en un paraje conocido según M. A. Motis (1995:9) como la Plana. Sin embargo, A. López (2003:231-232) sobre la base de la documentación notarial del siglo XV identifica este mismo lugar como Portexuelo, lindando con la Plana. Los cortejos fúnebres atravesaban la puerta de la Furiega y los enterramientos se realizaban aproximadamente a un kilómetro de distancia, en la falda de un cerro situado tras pasar una zona de eras hoy en día abandonadas.

Por otra parte existe constancia documental del hallazgo de seis inscripciones hebreas de carácter funerario, publicadas por primera vez por Fidel Fita (1888:15-20) y actualmente desaparecidas. Éstas fueron encontradas en otra zona, al pie del cerro de la Peña, lugar donde eruditos locales como Vicente de la Fuente situaban el cementerio judío. Cuatro fueron localizadas en $1690^{1}$, conservándose un calco correspondiente al epitafio de Mosé, hijo de Yosef ben Cabra (J. Casanovas, 2002:360). Otra fue hallada en la misma zona en $1882^{2}$. Finalmente, en 1956 se publicó otra lápida reutilizada en el exterior de la iglesia de la Peña, también quizás de carácter funerario pero muy deteriorada (A. López, 2003:231).

La que ha podido ser mejor estudiada, gracias a la publicación de un grabado, es la encontrada en 1882. Según Casanovas está dedicada a Semu `el, hijo de Rabí Selomoh, y "la opinión unánime de todos aquellos que han estudiado la lápida es que se trata de un epigrafe antiguo, posiblemente uno de los más antiguos de España exclusivamente en lengua hebrea", siendo su datación anterior al siglo XI (J. Casanovas 2002:362-363).

Según se extrae de la documentación fiscal, que recoge tributos como la pecha estudiada por A. López (2008:29, 47-48), la población judía de Calatayud tuvo un importante crecimiento cuantitativo durante la segunda mitad del siglo XIII, lo que sin duda debió repercutir en un desarrollo urbano de la propia judería. También Y. Baer se hace eco de esto, pues al parecer la extensión que alcanzó la judería de Calatayud ya en el siglo XIV hizo insuficientes las ocho sinagogas existentes, siendo necesario construir una nueva (I. Muñoz, 2003:168). La elevada capacidad contributiva, a la par que un indicador de la existencia de un elevado número de familias, también pone de manifiesto la existencia entre ellas de algunas particularmente acaudaladas durante dicha centuria (M. Diago, 2007:328).

Sin embargo, una serie de acontecimientos truncarán esta tendencia. Los desastres provocados por la llamada Guerra de los dos Pedros (1356-1369) afectaron físicamente a la población, situada de hecho en el mismo frente de lucha, pero será la conversión al cristianismo de una parte importante de la comunidad y la expulsión del resto las que causen su desaparición definitiva en el siglo XV. Según M.A. Motis (2005:128) Calatayud y su área de influencia pudo tener entre 750 y 900 judíos a fines del siglo XIII, pero en el fogaje de 1397 tan sólo se contabilizan 191 casas, lo que se traduciría en unos 760 a 860 judíos. A principios del siglo XV la población vuelve a remontar: A. López (2003:61) la cifra en unos 1000 habitantes según el fogaje del 22 de enero de 1405.

1 Vicente de la Fuente informó a la Real Academia de la Historia que: "Por los años de 1690, descubriendo un labrador de la ciudad de Calatayud unas ruinas á las espaldas de la I glesia colegial de Nuestra Señora de la Peña, oy casa de clérigos Menores de Francisco de Caraciolo y Angustia Adorno http://www.cervantesvirtual.com/servlet/SirveObras/12143069700697877317524/not0005.htm N_47, para ampliar una hera debaxo de unas casas muy paxizas, que miran al Oriente, encontró tres ó quatro sepulcros de piedra muy grandes, y en la testera de uno de ellos una piedra blanca de media vara en quadro; y haviendo hecho grande averiguación con personas doctas de España, no se ha encontrado quien la haya podido descifrar" (F. Fita, 1888:20).

2 Mariano de la Hoz publicó el hallazgo en el Diario de Calatayud del 9 de abril de 1882: "En las excavaciones practicadas con motivo de la construcción de un edificio en el barranco de las Pozas, ó barrio de la Consolación, junto á las eras, debajo de Nuestra Señora de la Peña se han descubierto varios sepulcros, que conservaban todavía restos humanos; y sobre uno de ellos, que mide 2,30 metros por 0,80, una lápida casi completa, marmórea con caracteres bastante raros" (F. Fita, 1888:19). 


\section{Primera fase de ocupación: maqbara islámica (siglo IX-1120)}

Entre los años 2005 y 2008 pudimos excavar una superficie de $2430 \mathrm{~m}^{2}$ en tres solares colindantes ${ }^{3}$ situados en una manzana delimitada por las calles Barrio Nuevo, Ronda Puente Seco y la antigua Nacional II (fig. 1). Con carácter previo a la construcción de nuevos edificios de viviendas, y a tenor de lo marcado por la ley, se llevaron a cabo excavaciones de urgencia en dichos solares. Los restos, una vez documentados, fueron desmontados para poder continuar con la excavación de los niveles arqueológicos subyacentes.

Gracias a los resultados de estas excavaciones arqueológicas se ha documentado por primera vez la ocupación medieval de esta área de Calatayud, situada en la margen derecha del barranco de las Pozas, debajo del cerro de la Peña y frente a la puerta de Terrer. En el análisis que realizaremos a continuación confrontaremos los datos arqueológicos obtenidos con las fuentes documentales hasta ahora estudiadas y publicadas por diversos autores.

La primera ocupación medieval, hasta el momento desconocida, consiste en un cementerio musulmán o maqbara atestiguada por unas 230 tumbas. El barranco de las Pozas debió servir de foso ante la muralla que se situaría en la margen opuesta, por lo que la maqbara a tenor de lo común se ubicaría extramuros y a poniente de la madina de Calatayud, cerca de alguna puerta de acceso al interior de la ciudad.

La mayor parte de las tumbas corresponden a la fase plena de ocupación, con una cronología califal y taifal (siglo X-1120). Los individuos, enterrados en fosas en algunos casos cubiertas por estructuras más o menos complejas de adobes, aparecen en posición de decúbito lateral derecho, con orientación NE-SO y con su rostro orientado hacia el sudeste. Asimismo se atestigua una fase más antigua, probablemente del siglo IX, que se evidencia por un claro cambio en la orientación de los enterramientos.

\section{Segunda fase de ocupación (siglos XII-XIII)}

Tras la conquista cristiana (1120), hallamos una nueva ocupación del terreno, que se mantiene fuera del perímetro amurallado. Corresponde a una serie de estructuras de habitación compuestas por muros de mampostería construidos con piedra aparejada en espiga y suelos de yeso muy alterados por construcciones posteriores (fig. 2). Así como algunos otros pavimentos de este mismo material asociados a pocetas que pudieran indicar algún tipo de actividad artesanal. Estos restos sólo aparecen en la parte sur de la zona excavada, en el solar de la calle Subida la Peña no 7.

Asociado al conjunto, aparece un cementerio cristiano (fig. 3) compuesto por cerca de 120 tumbas antropomorfas que sólo se ha documentado en el solar de la calle Subida la Peña no 7 . Los individuos aparecen inhumados sin ningún tipo de ajuar en posición decúbito supino con los brazos flexionados sobre el pecho o el vientre y con la cabeza orientada hacia el oeste. Las tumbas presentan en la mayoría de la ocasiones la característica cabecera semicircular excavada junto con el resto de la fosa en las arenas naturales. En algunas ocasiones, a cada lado del cráneo se colocan lajas verticales de piedra. Todas ellas se hallan cubiertas con grandes fragmentos, muy toscos, de piedras de yeso procedentes del entorno natural ${ }^{4}$.

El Real Convento de San Pedro Mártir, perteneciente a la orden de dominicos o de predicadores, fue fundado por Jaime I, según consta en un privilegio de fecha 11 de marzo

3 Solar de la calle Ronda Puente Seco n॰ 5 / Subida la Peña n 6, solar de la calle Barrio Nuevo n 1 angular a Ronda de Puente Seco no 7 y solar de la calle Subida la Peña no 7

4 La documentación planimétrica de las necrópolis quedó incompleta al quebrar la empresa constructora, sin que pudiesen conseguirse otros medios económicos para completar dicho trabajo de documentación". 


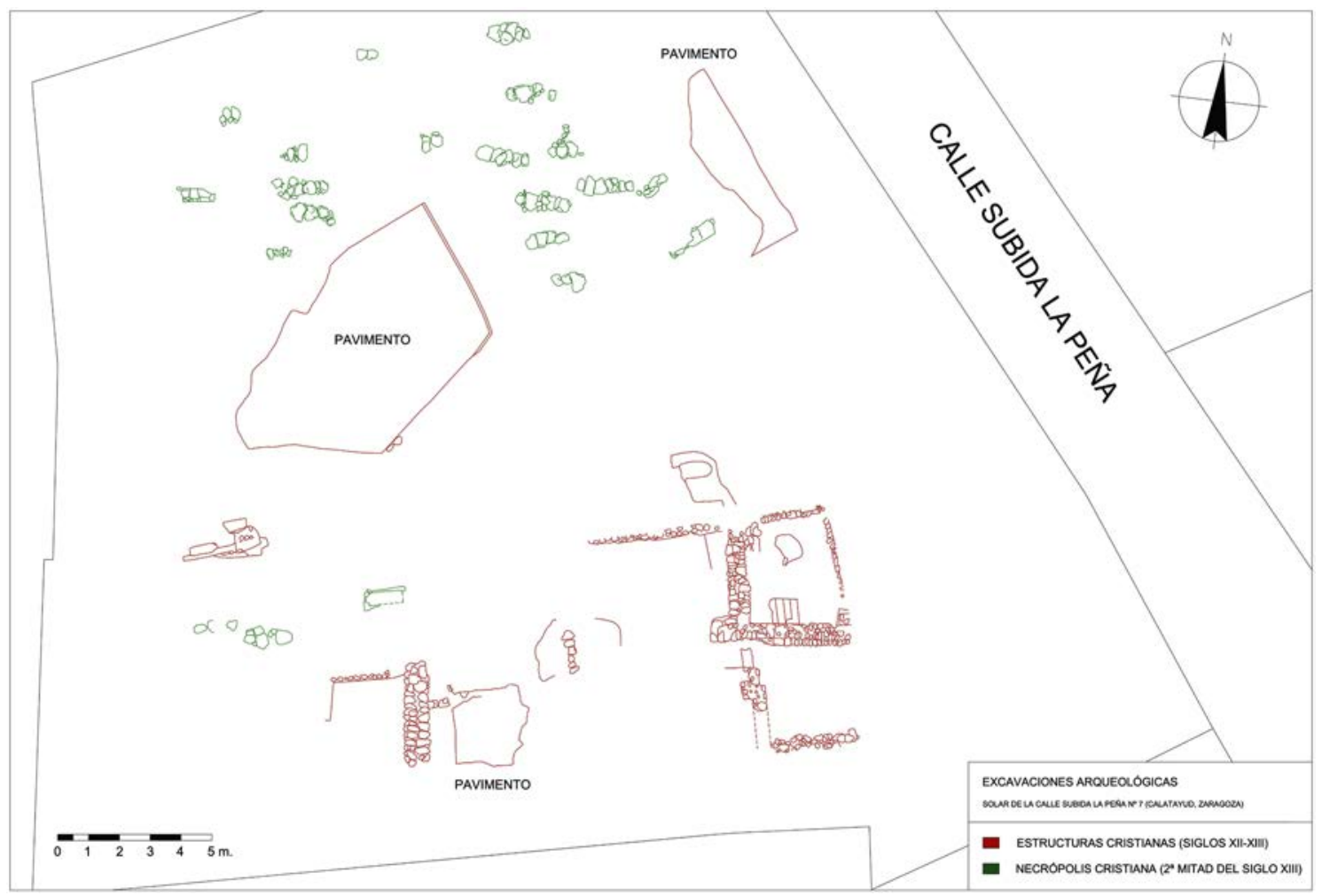

Figura 2. planimetría de las estructuras cristianas (siglos XII-XIII) y algunas de las tumbas que componen la necrópolis cristiana (segunda mitad del siglo XIII).

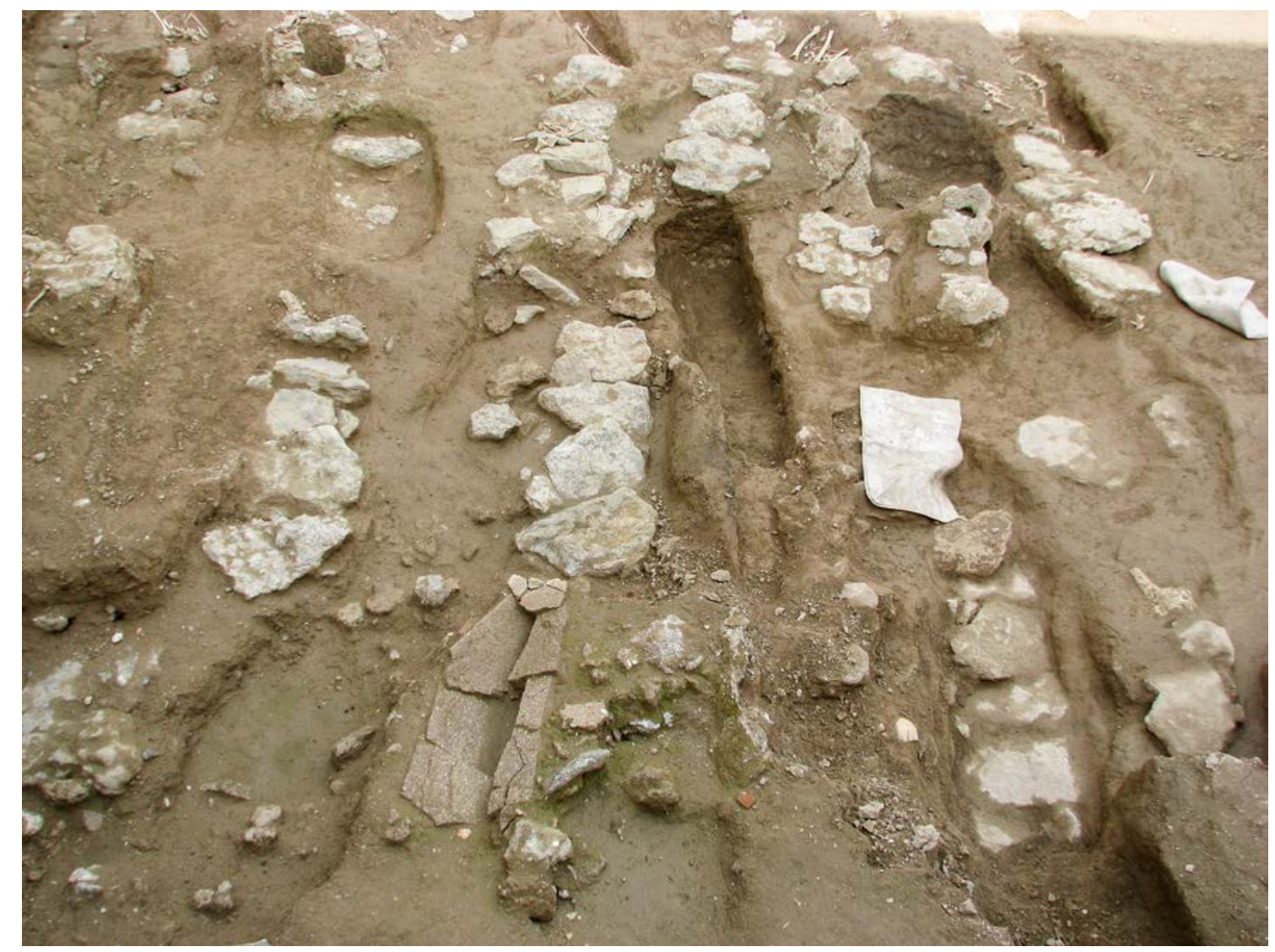

Figura 3. vista desde el oeste de la necrópolis cristiana relacionada con el convento de San Pedro Mártir. 
de $1255^{5}$. El primer convento se erigió extramuros, al principio de la vega, debajo del cerro de la Peña "y hacia la parte que hoy ocupan el convento de Carmelitas descalzos, y las eras fronterizas a la puerta de Terrer" (V. de la Fuente, reed. 1969:252); es decir, frente a la puerta de Terrer. No es casual esta ubicación tan cercana a la judería: es bien sabido que los frailes de esta orden mendicante se especializaron en la labor de la conversión de los judíos.

El convento fue destruido en 1362 por el sitio militar impuesto a Calatayud durante Guerra de los dos Pedros y provisionalmente reacondicionado en el mismo lugar, aun estando la ciudad ocupada por las tropas castellanas (V. de la Fuente, reed. 1969:18). Sería reconstruido definitivamente a partir de 1366 a pocos metros de distancia (en la zona donde actualmente se sitúan la avenida de San Juan el Real y la plaza de Marcial), pero ya al interior del recinto amurallado, del que formaba parte. Finalmente, sería demolido en 1856.

Comparando el registro arqueológico y el documental podemos interpretar estos restos estructurales aparecidos en la parte más baja de la zona excavada como dependencias auxiliares pertenecientes a dicho convento o en todo caso como nuevas viviendas cristianas atraídas por la fundación religiosa en la margen derecha del barranco de las Pozas. Los hallazgos cerámicos, principalmente a partir de varios ejemplos vidriados con decoración a molde, y la tipología de la necrópolis cristiana corresponden perfectamente con la horquilla cronológica indicada por las fuentes de la segunda mitad del siglo XIII.

La existencia de un área de inhumación fuera del perímetro urbano sólo puede explicarse en relación con este establecimiento religioso. La norma de la época era ser enterrado en el cementerio de la propia parroquia, aunque esta regla podía romperse mediante un pago a la parroquia donde debía ser enterrado el cadáver y otro pago al lugar que va a recibir el cuerpo, siendo los conventos uno de los lugares de destino más solicitados (M.C. García, 1989:95).

\section{Tercera fase de ocupación: una ampliación de la judería (siglo XIV)}

Aunque la judería ya había sido objeto de algunas intervenciones arqueológicas de carácter puntual, por ejemplo en la actual ermita de la Virgen de la Consolación, antigua Sinagoga Mayor (J.L. Cebolla, J.I. Royo y J. Rey, 1997:54-59), la excavación de estos tres solares ha ofrecido significativos hallazgos como para plantear que las viviendas encontradas debieron formar parte de ella. Pese a hallarse a escasos metros al sur de la muralla meridional de la judería y de la puerta de Toledo, son muy pocas las fuentes históricas que hacen referencia a la ocupación medieval de esta zona, situada en la margen derecha del antiguo barranco de las Pozas y al exterior de la muralla meridional de la judería.

Se ha podido documentar un conjunto de edificaciones que ofrecen una densa y compleja trama urbana que urbanísticamente responde a una ampliación a extramuros de la ciudad (fig. 4). Se trata de una manzana de nueva construcción limitada por espacios públicos. Al norte y al este por sendas calles que han quedado fosilizadas en la actual topografía urbana, en las vías Barrio Nuevo y Ronda Puente Seco respectivamente. Mientras que al oeste se abre una gran plaza rectangular ( $25 \times 15.30 \mathrm{~m}$.). La cronología por nosotros establecida en una primera aproximación, a partir de los restos materiales, lleva a concluir un inicio de la ocupación urbana en torno a los primeros años del siglo XIV. Entre los escasos materiales hallados en las fosas de fundación de varios muros se halla un dinero de vellón de Jaime I (1213-1276).

La manzana se construyó en la ladera sur del cerro de la Peña, que presenta un fuerte desnivel de norte a sur, por lo que las casas

5 J.R. Olalla (2005:140). Según este autor, los dominicos "están documentados en Calatayud desde 1255, aunque llegaron antes". Sobre la historia del convento, véase la recopilación facsímil de las publicaciones al respecto realizada por A. Sanmiguel (2006). 


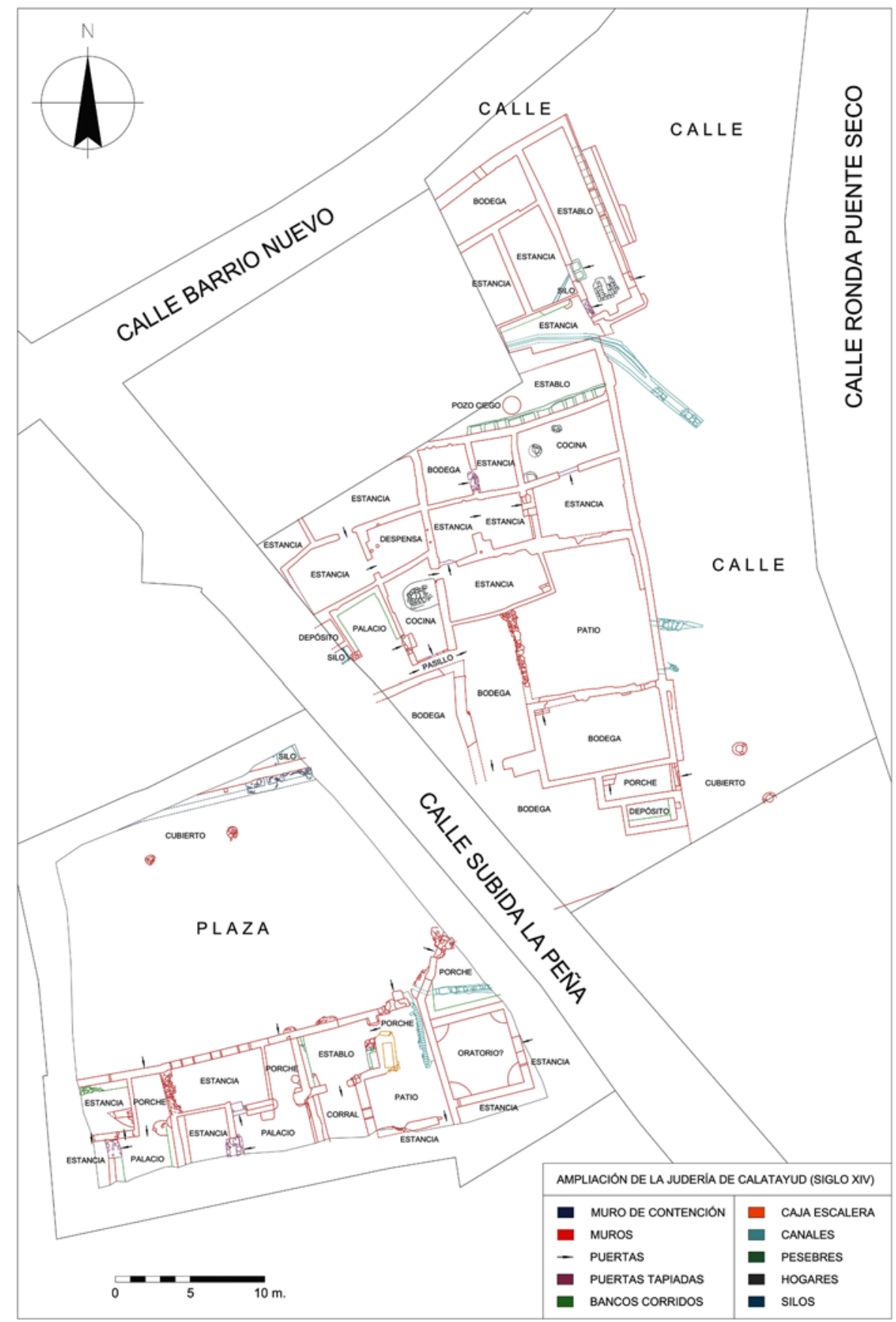

Figura 4. planimetría de la ampliación a extramuros de la judería (siglo XIV).

se adaptan al relieve mediante la construcción en diferentes terrazas, como se puede observar en el muro de contención que cierra la plaza al norte y sobre el que se sitúan nuevas estructuras. Se han localizado varios canales, generalmente construidos con ladrillos y argamasa de yeso, cubiertos por losas de piedra que desaguan las aguas fecales hacia los espacios comunes.
Tradicionalmente la piedra de yeso es la materia prima más abundante de la zona de Calatayud. Una vez cocida en hornos se obtenía el yeso o aljez, con cuya argamasa se levantaban y se enlucían los muros o se preparaban los suelos. La técnica constructiva de este conjunto consiste en un mortero al que se añaden piedras medianas y grandes del mismo material pero sin transformar. Con esta 
mezcla se rellena una estructura de madera consistente en formar cajones prismáticos de encofrado con varias tablas unidas por traviesas verticales de madera llamadas costales. En sentido horizontal, y perpendicularmente a los tableros, se disponían pasadores, llamados agujas que podían o no atravesar el cajón de lado a lado y servían para darle rigidez al encofrado en unos casos o simplemente para sujetarlo a la obra. También se utilizan cuerdas de esparto para dar rigidez y evitar que el cajón se abra al verter el material, e incluso pueden atravesar todo el ancho del cajón y atarse de costal a costal. Así sucede siempre en la parte superior, o puede atarse al clavo - la cuña que sujeta la aguja, cuya función entonces es solo la de sostener el encofrado. De no usar cuerdas, se debe sujetar las agujas a los costales o las tablas con cuñas o clavos.

Estos elementos de encofrado han dejado su clara huella en las paredes. Así podemos observar las líneas de unión en relieve entre tabla y tabla, con unas medidas que fluctúan entre 35 y $15 \mathrm{~cm}$. de anchura, mientras que su longitud rondaba los $1.94 \mathrm{~m}$. Las agujas también han dejado su huella tras ser retiradas, coincidiendo su separación con la longitud de algunos de los tablones. En dos muros se han hallado restos de ollas usadas, desde la mitad de la panza hasta el fondo, insertadas en la pared y cuya utilidad desconocemos.

Los suelos de las habitaciones no son ni mucho menos uniformes, de modo que encontramos algunos fabricados con argamasa de yeso o arcilla apisonada, mientras que la mayoría se componen simplemente de tierra batida. En algún caso aparecen improntas circulares en el suelo de yeso para el apoyo de tinajas, lo que nos indica que esta habitación sirvió de despensa.

El acabado final de las estancias se realiza con gran sobriedad mediante un enlucido blanco de yeso, a veces de tal finura que se consigue un blanco alabastrino de gran dureza. Tan sólo en un cuarto se ha detectado decoración pictórica compuesta de líneas rojas verticales y horizontales sobre el enluci- do. En una reforma posterior, la puerta de la estancia fue tabicada y la pintura tapada por un nuevo mortero blanco.

Aunque no disponemos de viviendas completas, los restos excavados parecen indicar que se trata de la típica casa aragonesa de dos plantas y bodega, según la ha descrito M.A. Motis: "un sótano con cillero o granero; una planta baja con un porche, varios palacios o estancias destinadas a almacén o usos laborales, una masadería (amasadero) -en las más humildes basta con una artesa o bacias de masar-, algunas retretas y un corral o un establo, un pozo; y la primera planta con la cocina, el estudio y las cambras o dormitorios" (2005:130). No se han podido identificar habitaciones dedicadas a la realización de actividades artesanales.

Es clara la existencia de numerosas bodegas de planta rectangular y notable tamaño, que a veces conservan en su alzado los agujeros para encastrar las vigas de madera sobre las que se desarrollaba el piso superior.

Se ha podido establecer la función de diversas estancias de la planta baja (fig. 5): porches de entrada; palacios, que dan acceso a otras habitaciones y que en ocasiones podrían ser patios abiertos, como uno que conserva los restos de la escalera de subida al piso superior; cocinas, donde aparecen hogares circulares en el suelo, realizados con losas de piedra y ladrillos; despensas; simples pasillos; silos para grano u otros tipo de depósitos para el almacenaje. En muchas de las salas aparecen bancos corridos junto a los muros (fig. 6) y, a veces, la puerta de entrada a la casa se halla precedida de un espacio cubierto apoyado en postes de madera. También encontramos varios establos con pesebres para alimentar a animales de carga tan necesarios como caballos, asnos o burros y donde también podrían criar pequeños animales domésticos básicos para la alimentación, como las aves de corral. Esta misma funcionalidad podría tener una estancia rectangular (11.40 × $2.70 \mathrm{~m}$.) que presentaba siete hornacinas alineadas, con perforaciones en la parte inferior para colocar 


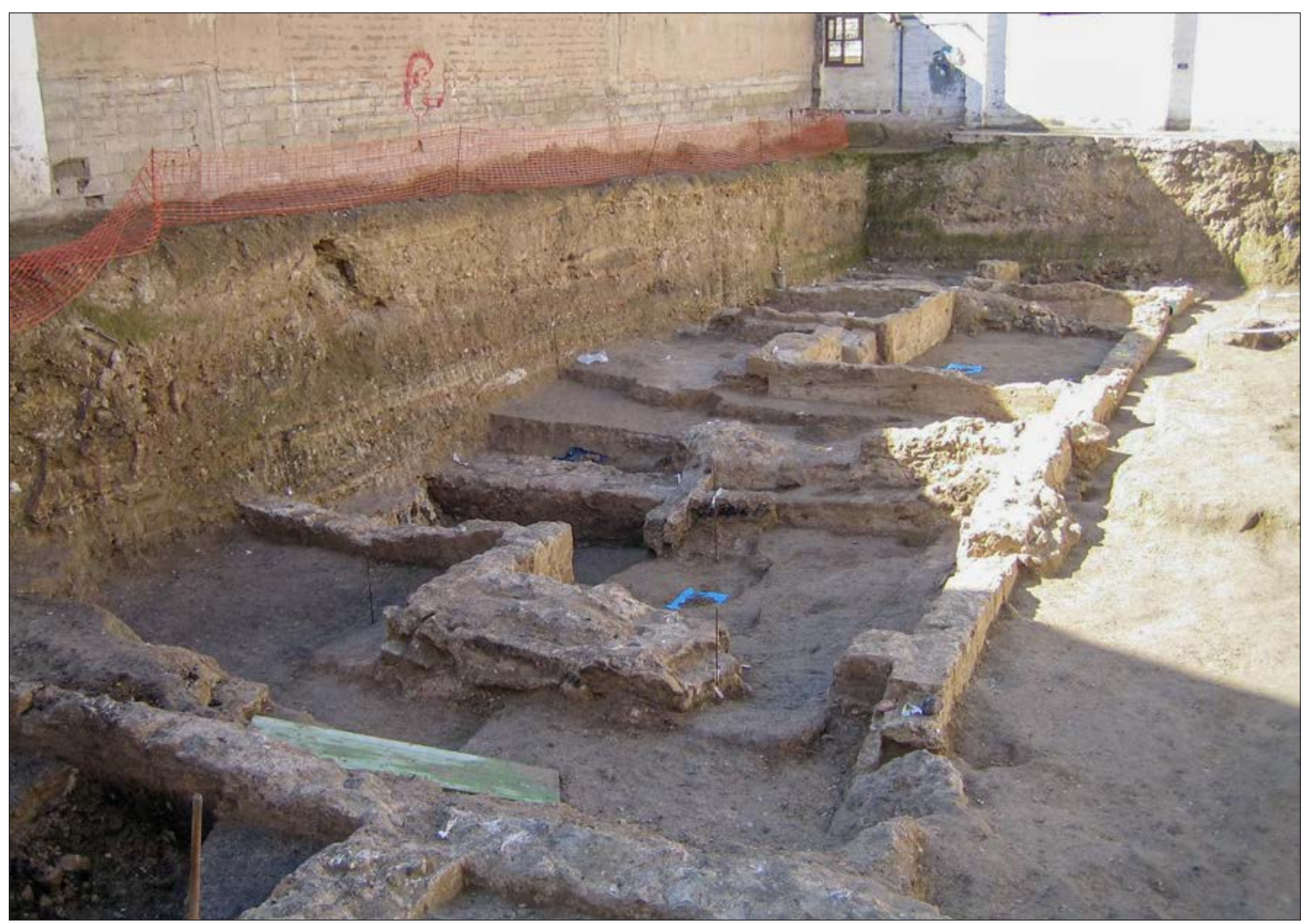

Figura 5. viviendas situadas al sur de la plaza con porche, palacio o patio y estancias.

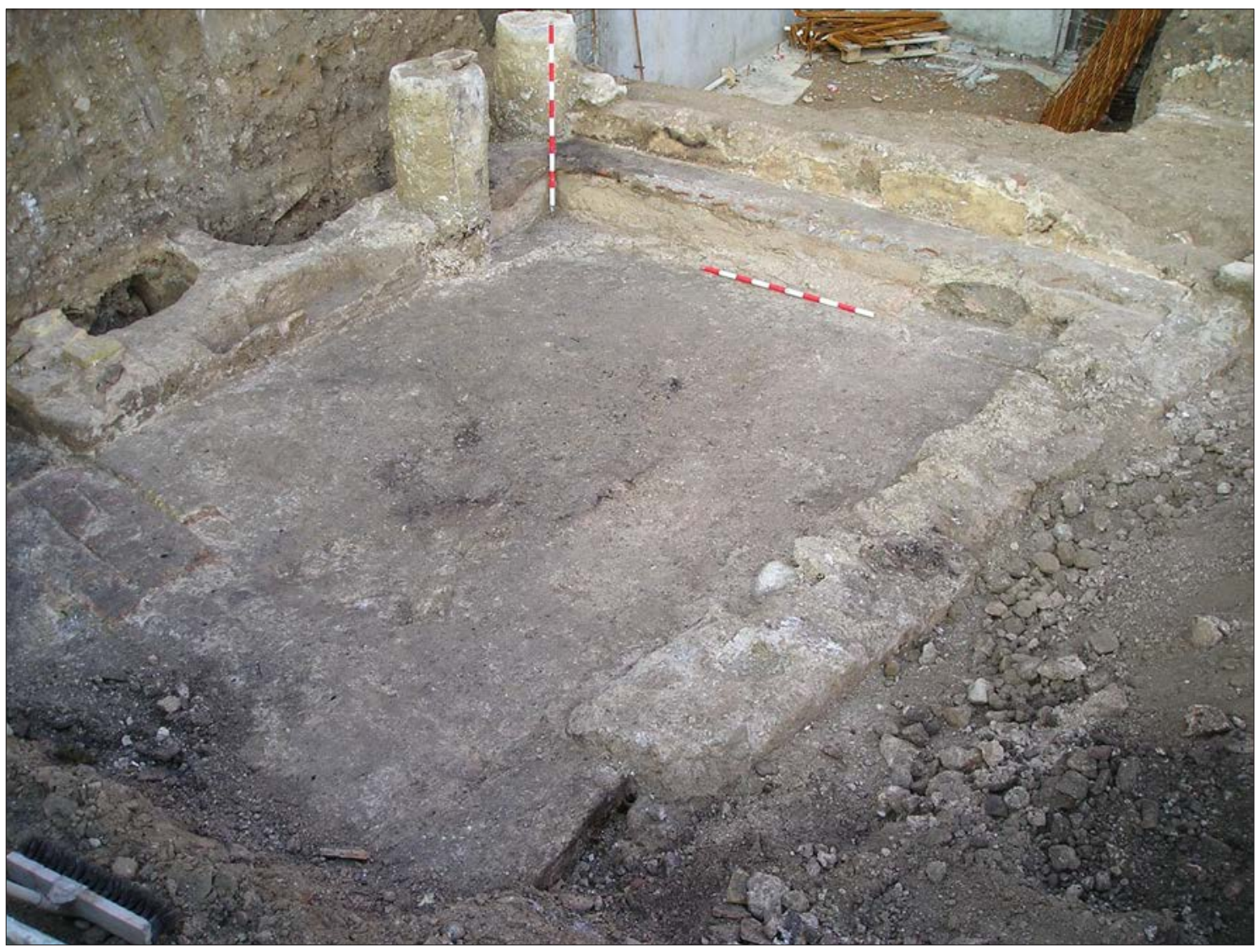

Figura 6. habitación con bancos corridos y suelo de yeso. 
algún tipo de estructura de madera, y dos piletas de escasa profundidad (fig. 7).

Llama la atención una estancia cuadrangular $(4.75 \times 4.80 \mathrm{~m}$.) que presentaba puerta de entrada central y suelo de mortero de yeso. Unos apoyos macizos en forma de cuarto de círculo, situados en las esquinas, posiblemente denotan el cubrimiento mediante bóveda de crucería (fig. 8), aunque no aparecieron

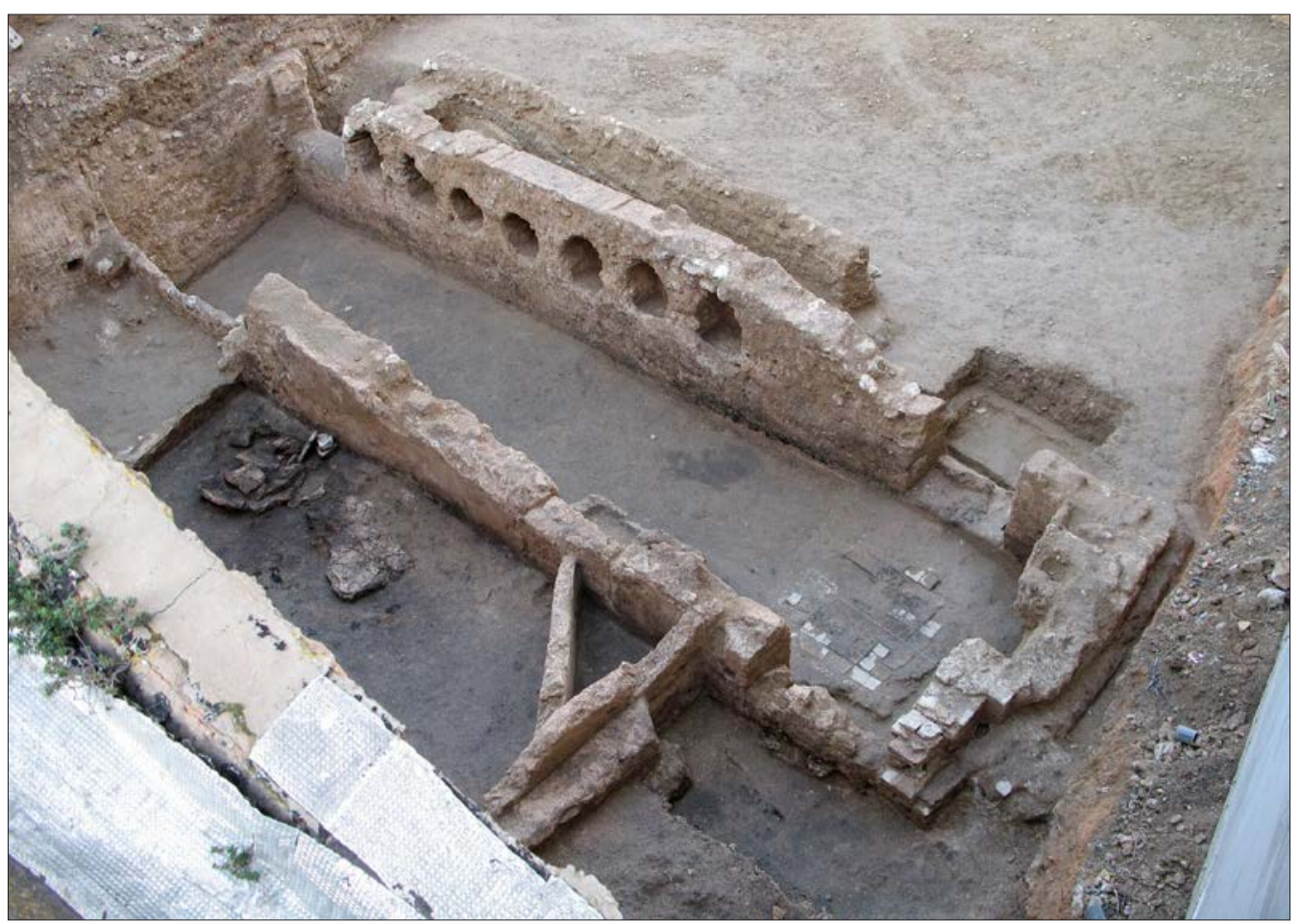

Figura 7. vista de una vivienda con un posible establo.

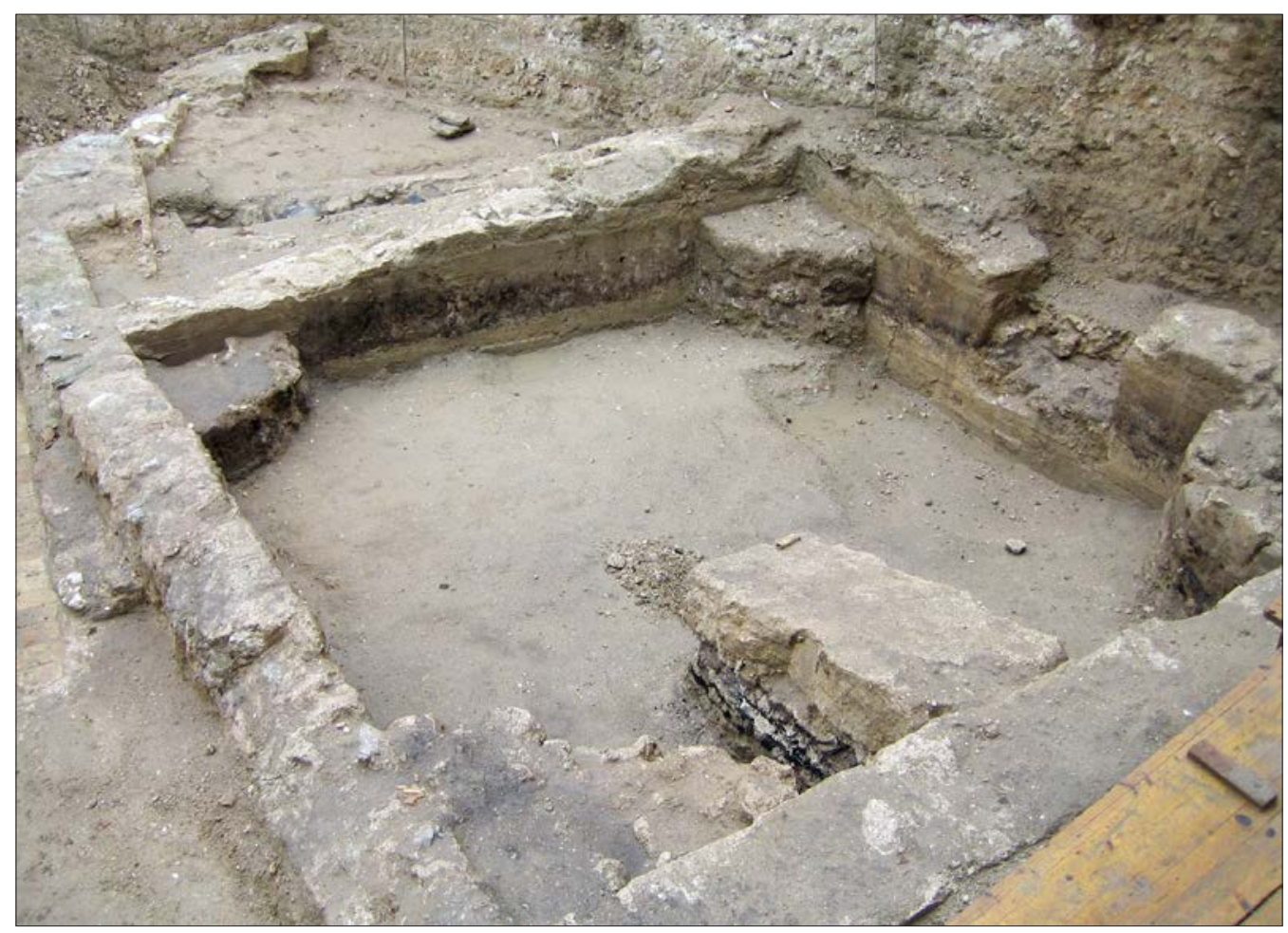

Figura 8. probable oratorio privado (midrás). 
otros restos materiales que confirmen esta hipótesis. Ninguna otra habitación ostenta este tipo de estructura, por lo que, con la debida prudencia, quizás se podría identificar con un pequeño oratorio privado, como los que ha documentado Asunción Blasco (2003). En este sentido, su planta guarda similitud con la planta de la sinagoga de Córdoba (J. Peláez, 2006), aneja a una casa y precedida de un patio como en el caso bilbilitano. El oratorio (midrás) podía ser erigido para uso restringido de una familia, cofradía o asociación privada, siendo Calatayud la ciudad aragonesa con un mayor número de ellos identificados (A. Blasco, 2003:210-213).

El interior de las estancias se encontró relleno por la caída por desplome de paredes y tejados tras un incendio devastador. El incendio supuso, primero, la acumulación sobre el suelo de las cenizas provenientes de la quema de todos los elementos de la vivienda realizados en madera. Inmediatamente después se desplomaron los tejados, formados por tejas del modelo árabe aplastadas por el peso, y los suelos de las plantas superiores junto con placas de yeso o aljez de los revestimientos de los muros y techos. Esto pudo seguir manteniendo las altas temperaturas, que al final harían caer hacia el interior de las casas sus muros perimetrales. Por lo tanto, el componente principal de estos estratos son los fragmentos de paredes de yeso o aljez, así como los revestimientos de las mismas y los de techos.

La aparición, entre este conjunto, de estructuras de yeso de forma abovedada muy aplastadas que pudieran pertenecer a los pisos superiores, indican la existencia de dos plantas en estas casas. Se pudo documentar un fragmento de enlucido, seguramente perteneciente a una de esas plantas superiores, que muestra un interesante grafito a carboncillo que describiremos más adelante (fig. 9).

Sobre el suelo de las habitaciones se extiende un nivel de cenizas de escasa potencia con grandes fragmentos de maderos carbonizados de la techumbre, así como numerosos clavos de hierro utilizados para mantener la trabazón de ese armazón. Junto a estos materiales

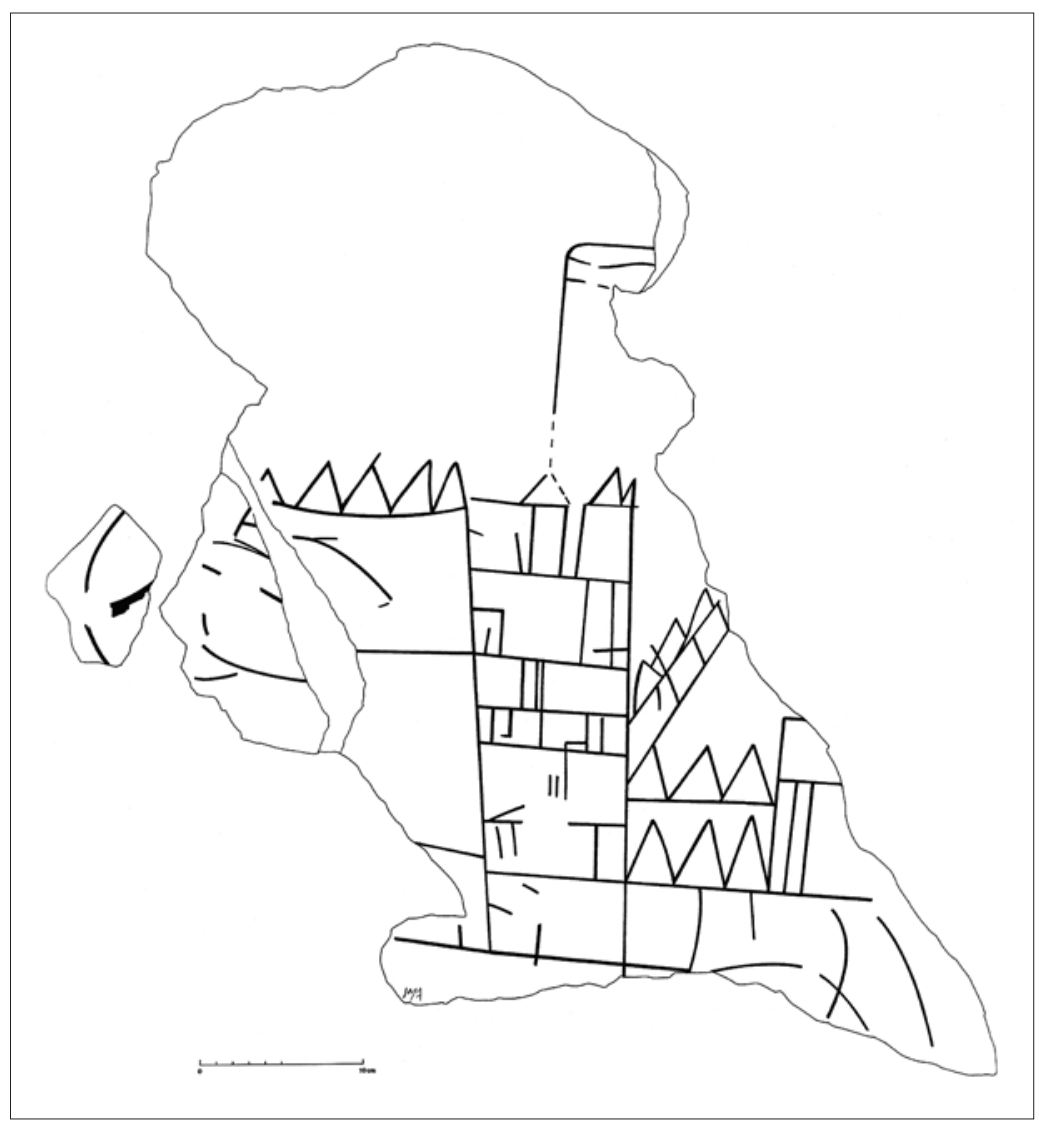

Figura 9. fragmento de grafito mural a carboncillo. Dibujo: Inmaculada Soriano. 
hallamos otros elementos metálicos de uso cotidiano: ganchos, argollas, una posible llave partida, tijeras, calderos,... Aplastadas sobre el piso aparecen producciones cerámicas de la primera mitad del siglo XIV como cerámica procedente de los alfares turolenses con decoración de verde-manganeso o cerámica de reflejo dorado de tipo malagueño de procedencia levantina.

El uso de estas cerámicas evidencia un alto poder adquisitivo, aunque su número, a veces no muy elevado, parece indicar que dio tiempo a sus moradores a recuperar los elementos más suntuosos. En este nivel de destrucción, en el interior de dos estancias, se han podido recuperar fragmentos de lámparas de Januká (fig. 10 y fig. 11, 2).

Durante el período en que las casas estuvieron en uso hasta su destrucción sufrieron continuas reformas: el cierre de puertas, la construcción de nuevos tabiques que dividen habitaciones o los sucesivos enlucidos de las paredes, como por otra parte es normal en cualquier vivienda.

Recientes trabajos de investigación de A. López (2003) sobre la judería bilbilitana han planteado, a partir de las fuentes documentales conservadas (fundamentalmente archivos notariales, cuya mayor parte pertenece al siglo $X V$ ), la definición concreta de los diferentes barrios que conformaban la judería de Calatayud: Burgimalaco, Villanueva y el Varranco. De esta documentación tardía, y de lo que

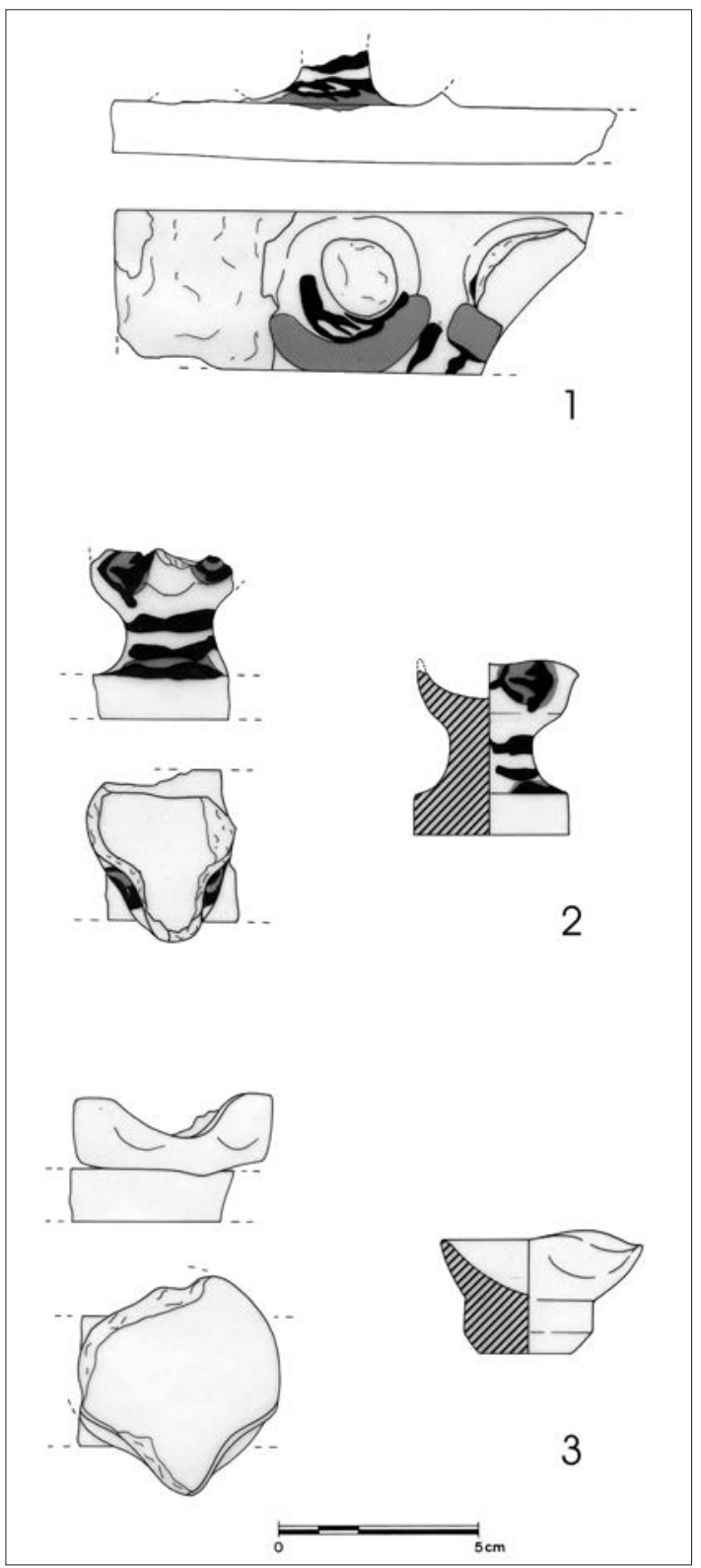

Figura 11. Janukía no 3 (1), janukía no 2 (2) y janukía no 4 (3). Dibujo: Inmaculada Soriano.

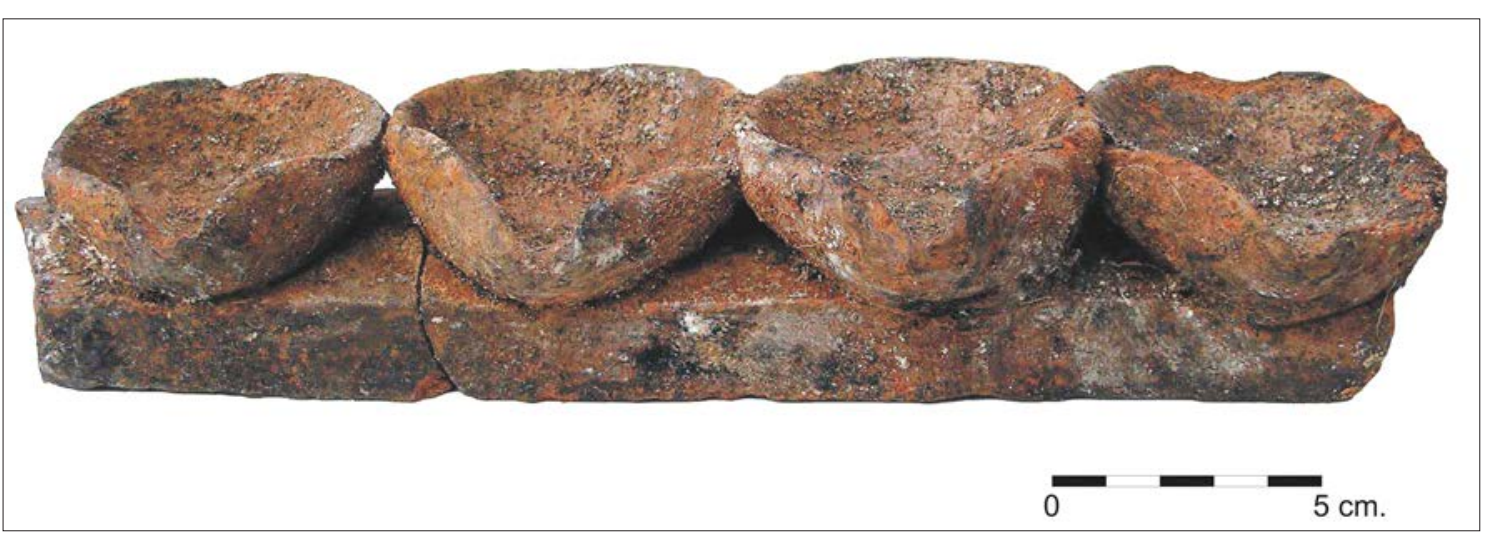

Figura 10. Janukía no 1 en el momento de su hallazgo. La pieza fue depositada en el Museo de Zaragoza y posteriormente fue preparada para su traslado al de Calatayud, en estos momentos no resulta posible su examen. 
queda de documentación del siglo XIV, podemos reconstruir algunos acontecimientos del desarrollo urbano de Calatayud.

El 4 de noviembre de 1322 se fecha un mandato dirigido por el rey al baile de Calatayud para que hiciese ensanchar una calle de la aljama de los judíos, donde vivían Mosse Ven el Vayo y Jaco Quatorce (A. López, 2003:61). Desconocemos el punto exacto de esta ampliación, pero no deja de ser significativo que en los inicios del siglo XIV el mismo monarca enviase orden a Calatayud para permitir el desarrollo físico de la judería.

En el siglo XV Burgimalaco, vocablo que puede interpretarse como barrio del Rey (A. López, 2003:78), se define en la margen derecha del barranco de las Pozas (hoy nivelado en la calle Ronda Puente Seco), con límite occidental en el llamado Monte viexo o montículo de la Peña. Al norte en la actual calle del Barranco de las Pozas, a oriente en la misma calle Ronda Puente Seco y al sur en la actual calle de la Escalera de la Peña, por donde discurría la desaparecida muralla donde se emplazaba la puerta de Toledo (A. López, 2003:80-83). Cabe decir que ésta debía ubicarse a poco más de diez metros de la esquina noreste del solar excavado. Tal como queda así definido el conjunto, parece evidente que al sur de esos límites, y ya en el siglo XV, no había nada que pudiera ser considerado en la documentación como edificaciones susceptibles de compra o venta, algo que hemos podido documentar y que posteriormente trataremos.

Comparando los registros arqueológico y documental, podemos apuntar que antes del siglo XIV en la margen derecha del barranco de las Pozas existían nuevas zonas de residencia. En la parte alta, junto a la puerta de Toledo, y al exterior de la muralla meridional de la judería, se habían instalado nuevas viviendas que, a juzgar por los restos cerámicos de carácter ceremonial localizados debieron pertenecer a la mencionada comunidad. Los hallazgos de dos fragmentos de janukías en el interior de las viviendas excavadas, elementos únicamente utilizados por la comunidad judía, nos permiten plantear la realidad de una ampliación del barrio judío de Burgimalaco al sur de la calle de la Escalera de la Peña, límite meridional amurallado de la judería.

En la parte más baja del barranco se hallarían las estructuras quizás pertenecientes al Real Convento de dominicos de San Pedro Mártir. Ambas zonas quedarían destruidas en el gran asedio castellano de 1362 y no se volverían a ocupar.

\section{La destrucción de esta nueva man- zana de la judería (1362)}

Resulta evidente que los materiales muebles localizados en los niveles de destrucción de las viviendas cuentan con una clara referencia cronológica que ha de situarse entre el 11 de junio y el 29 de agosto de 1362; es decir, debido a la destrucción que supuso el sitio militar impuesto por Pedro I para la conquista de Calatayud durante la Guerra de los dos Pedros. Las producciones cerámicas que fueron recuperadas se pueden considerar un magnífico exponente de las utilizadas a mediados del siglo XIV al haberse recuperado sobre el suelo destruido en fechas tan concretas.

El gran cronista Jerónimo Zurita describe pormenorizadamente los acontecimientos que se sucedieron hasta la rendición de la ciudad a las tropas castellanas ${ }^{6}$. Tras tomar las cercanas fortalezas de Ariza, Ateca, Terrer, Moros, Cetina y Alhama, el 11 de junio de 1362 un formidable ejército castellano estableció el sitio de Calatayud ${ }^{7}$. Ante la demanda de los

6 Jerónimo Zurita, Anales de Aragón, Libro IX, Capítulos XLI y XLII.

7 "Treinta y seis máquinas, doce mil de caballo y treinta mil de pie había sobre Calatayud. Desde que el rey de Castilla puso su real sobre Calatayud se fue acrecentando su ejército de manera que llegaban a ser doce mil de caballo y treinta mil de pie; y comenzaron a combatir la villa terriblemente con su artillería, que era la mayor que se hubiese antes visto en España, porque había en su campo treinta y seis máquinas que entonces llamaban ingenios, todos de batería” (Zurita, Anales, Libro IX, Capítulo XLI). 
sitiados, Pedro IV promete enviar refuerzos capitaneados por el conde de Osona. A principios de julio el monarca aragonés por fin ordena la marcha del conde de Osona. Éste se reune con las tropas de Pedro de Luna y toman camino hacia Daroca, desde donde parten hacia Calatayud el 13 de agosto de 1362. Tras un intento fallido de entrar en la ciudad, y alertados los castellanos de su presencia en Miedes, se puso cerco al lugar, consiguiendo la rendición de las fuerzas de socorro. Los sitiados, perdida toda esperanza, solicitan del enemigo un plazo de cuarenta días para pedir amparo del monarca aragonés y, si cumplido tal tiempo no se recibiera, se rendirían. Pedro IV da licencia a sus vasallos para la rendición ante la imposibilidad de enviar refuerzos y, transcurrido el plazo establecido, el 29 de agosto de 1362 se produjo la capitulación de Calatayud. Tras la conquista se procedió a la inmediata reparación de los castillos y las murallas, dejando Pedro I el mando de la plaza a García Álvarez de Toledo.

La lucha fue tenaz. Muchos caballeros y ciudadanos murieron peleando y defendiendo las torres y muros, como dice Zurita: " $Y$ cada día se combatía la villa, unas veces toda ella a la redonda por todo el ejército y otras en ciertos lugares y portillos; y batían los muros con diez y seis máquinas y con toda la batería que en aquel tiempo se usaba en grandes combates, con escalas, manteletes y gatas y con otros artificios asi de noche como de día. Y esto se ejecutaba con tanta furia que parecía imposible poderse defender. En estos combates recibieron los enemigos mucho daño, porque murieron en ellos diversas personas de cuenta, saliendo los de la villa fuera a pelear con los enemigos; y esto se hacía tan ordinariamente que fue necesario que el rey les enviase a mandar que no saliesen a pelear fuera de los muros".

El mismo cronista informa de la gran destrucción que sufrió la entonces villa de Calatayud durante el asedio: "como cada día se iba más estrechando el cerco y se apoderaron del monasterio de predicadores que estaba fuera del muro y con la batería derribaron la iglesia de los frailes de san Francisco".
El convento de predicadores no es otro que el Real Convento de San Pedro Mártir, arruinado porque "allí se encastilló D. Pedro el Cruel para combatir el edificio de la Peña y a la puerta fortificada; quedando el convento completamente derruido" ( $V$. de la Fuente, reed. 1969:252). Noticia confirmada por Zurita: "en los combates pasados habían derribado los enemigos el monasterio de San Francisco, y les habian hecho un fuerte desde el monasterio de San Pedro Mártir hasta el de Santa Clara, y tenían por aquella parte los muros por cuarenta brazas en cuentos" (Libro IX, Capítulo XLII). Es lógico pensar que el asedio de las tropas y la maquinaria pesada de guerra establecido por Pedro I desde el citado recinto religioso hacia el castillo de la Peña y la puerta de Toledo supuso la absoluta destrucción de todos aquellos edificios que se encontraran entre los contendientes, es decir, el nuevo barrio de la judería de la orilla derecha del barranco, situado ante la muralla de la ciudad. Cabe recordar que este sector fue el elegido por el monarca castellano para lanzar su ataque final sobre Calatayud.

Como bien subraya M.A. Motis (2005:128), buena parte de la judería debió ser duramente castigada por los impactos de proyectiles de catapulta en estos intentos de tomar Calatayud por su flanco occidental, defendido por el castillo de la Peña. En este sentido resulta interesante señalar la existencia de un documento de 1367 según el cual fueron premiados por Pedro IV con el privilegio de ser librados de la obligación de alojar como huéspedes a cristianos en sus casas "dos individuos pertenecientes a dos conocidas familias de judíos francos, Salamón Abendahuety Tadroç Abentilca, quienes, según reza el privilegio de concesión, la recibieron en compensación por haber sido destruidas sus casas durante la invasión castellana, y por los muchos servicios que habían prestado al tesorero real" (M. Diago, 2007:338).

En marzo de 1366 Pedro IV había recuperado la plaza de Calatayud, concediéndole el título de ciudad como recompensa. Una de sus primeras medidas fue reparar los muros 
de la ciudad, muy especialmente los de la judería, según Orden del 22 de junio de $1367^{8}$. La muralla sur se reedificó con paredes mucho más sólidas y gruesas; incluso la Sinagoga Menor, que estaba pegada a ella, tuvo que ser "partida por el medio" para conseguirlo (A. López, 2003:65). Tras certificar que la "aljama Calatayubii propter Castelle ad destructionis articulum fere deducti estis", el rey concedió en julio de 1371 la equiparación jurídica con los cristianos (M.A. Motis, 2002:82).

Hasta finales de la centuria se procede poco a poco a la reconstrucción de los conventos y edificios arruinados durante el sitio, en especial los de dominicos, franciscanos, Santa Clara y de la Peña, "procurándose colocar dentro del recinto fortificado los que estaban antes extramuros" (V. de la Fuente, reed. 1969:252). Por lo tanto, esta nueva manzana de la judería correría la misma suerte que el convento de dominicos tanto en su destrucción como en su restauración.

Según documenta M.A. Motis (2005:129), en 1398 se impidió a los cristianos "construir viviendas en el exterior de la muralla que protegía dicha judería". También algunos intentos para extender las juderías fueron frenados por decretos como el de Martín I (27 de marzo de 1398), que prohibió a los judíos vivir entre los cristianos y fuera de los muros de las juderías.

Sin embargo, estos decretos fueron superados por las realidades locales. Cuando en la segunda mitad del siglo XIV las autoridades de Calatayud permiten la ampliación de la judería, debido a la alta densidad de población, lo hacen hacia el interior de la ciudad. El lugar elegido para la nueva ampliación de la judería será la Villanueva o Barrionuevo ${ }^{9}$ de la margen izquierda del barranco de las Pozas, y no el lugar que ocupaba con anterioridad (la ladera sur del cerro de la Peña en la margen derecha del barranco), zona tal vez considerada como insegura tras la amarga experiencia de la guerra y quedando en el olvido su existencia hasta las excavaciones arqueológicas por nosotros realizadas.

\section{Evolución de este área periurbana}

Sobre las ruinas de las viviendas derruidas se acumularán los residuos provenientes de la reconstrucción de la ciudad. Se confirma en el registro arqueológico, que documenta la deposición paulatina de un amplio conjunto de niveles arqueológicos, generados por procesos de deposición y asociados a un vertedero establecido sobre la margen derecha del barranco de las Pozas durante la segunda mitad del siglo XIV y el XV. La riqueza en cenizas y restos de materia orgánica indica su acumulación como basurero, pero al mismo tiempo destaca la presencia de una considerable cantidad de piedras y desechos de construcción (ladrillos, tejas, yeso,...).

Este enorme basurero, con una potencia de más de dos metros, arroja un altísimo porcentaje de producciones cerámicas del siglo XIV, además de cerámicas ya del siglo $\mathrm{XV}$. Aparte de las formas comunes y vidriadas (ollas, tapaderas, cántaros, morteros, candiles de pellizco,...), destacan las producciones esmaltadas (escudillas, jarras, morteros, platos,...). Se trata de las conocidas series con decoración de verde-manganeso, de reflejo metálico combinado con el azul cobalto, de reflejo metálico y la loza con decoración azul cobalto procedentes de talleres locales y de los de Teruel, Paterna o Manises. También son de destacar algunas piezas comunes, como jarras y cántaros, con decoración pintada en manganeso y de gusto mudéjar procedentes del Levante. En este nivel de vertedero se han recuperado otros dos fragmentos de janukías (fig. 11, 1 y 3).

8 La aljama volvió a exigir que los judíos francos contribuyesen en el pago de los gastos "in operibus murorum et vallorum et in retinentia castri de la juderia" (M. Diago, 2007:337).

9 Al norte limitaba con la Cuesta de Santa Ana, al sur con la muralla y un postigo de la judería, al este con el barranco de las Pozas y al oeste con el barrio de la Villanueva cristiana (plaza de la Higuera y Bañuelo Alto). A. López, 2003:81. 
Sobre este particular existe otro testimonio documental. El 11 de enero de 1390 las autoridades municipales solicitan de la aljama medios económicos para la reparación y limpieza de los muros y las talladas o fosos de la ciudad. Ésta, amparándose en sus privilegios, se negaba porque nunca habían tenido obligación de reparar los muros, sino en lo que tocaba a la judería, "es a saber, de la partida de Sancta María de la Peña, puyando ent a la torre mocha alrededor", pero que nunca habían tenido que limpiar el foso. Alegan los cristianos, que éste se había cegado por la tierra que habían amontonado algunos de la judería en el barranco. Por fin, convinieron en reparar los adarves desde la Peña hasta la puerta de Torre Mocha, y con respecto al foso, "que los ditos judios apresent, monden e limpien la tajada de la puerta de Terrer, es a saber, de la puerta de la judería hasta el cantón de la iglesia de los prehicadores primero, juxta et segunt la dita ciudat fará las otras talladas en derredor" (V. de la Fuente, reed. 1969:231).

Sin duda resulta esclarecedor que 28 años después del sitio castellano el municipio bilbilitano imponga a la aljama la limpieza del foso o tallada que iba desde la muela del Santuario de la Peña hasta la iglesia de los predicadores, la reconstruida iglesia de San Pedro Mártir, porque los judíos lo habían rellenado con tierra (A. López, 2003:65). Esa colmatación, que debió ser retirada en la parte del cauce del barranco para mantener libre el foso, es la que nosotros hemos encontrado acumulada como basurero sobre las ruinas de las edificaciones destruidas en la guerra y que arroja un altísimo porcentaje de producciones cerámicas del siglo XIV.

La zona quedará yerma de toda población hasta bien entrado el siglo XX, siendo utilizada como área destinada a trabajos agrícolas, popularmente conocida como las eras de Terrer según testimonio de Vicente de la Fuente. A partir del siglo XIV tan sólo se ha constatado la existencia de una estructura rectangular de unos $188 \mathrm{~m}^{2}$ que podría pertenecer a un recinto para albergar ganado y que debió estar en uso durante el siglo XV.

\section{Una vista de la puerta de Toledo}

Como ya hemos avanzado, en una de las estancias situadas más al norte de la manzana, muy cerca de la puerta de Toledo, se pudo hallar en el nivel de destrucción un fragmento de enlucido (40 x $60 \mathrm{~cm}$.), seguramente perteneciente a una planta superior y que conservaba trazos a carboncillo de un grafiti (fig. 9). Dado su precario estado de conservación, aplastado y muy fragmentado, se realizó una detallada documentación fotográfica y el calco in situ de la parte conservada del mural antes de su levantamiento.

Lo componen dos capas de mortero. La inferior, con un grosor de $5 \mathrm{~cm}$., fue el primer revestimiento de la pared de tapial. Con posterioridad fue repiqueteada para conseguir la mejor adherencia de un segundo revoque de menor potencia con superficie de acabado blanco y fino sobre la que se realizó el dibujo.

En el centro se sitúa el elemento mejor conservado, que puede ser interpretado como una torre en la que se han detallado mediante algunas líneas horizontales y verticales un convencional despiece de los sillares que la formaban, algunas muy juntas y pequeñas tal vez puedan indicar saeteras. Rematan el elemento unos merlones triangulares. Sobre ellos, y en el centro, una raya vertical finalizada por tres perpendiculares a la derecha, que se puede interpretar bien como una construcción posterior, bien como un poste con estandarte. A la izquierda del baluarte y en primer plano, continúa otro edificio, posiblemente otra torre compuesta por tres alturas y con los mismos motivos defensivos en el techo. A la derecha se disponen dos alturas en horizontal que también cuentan con merlones y almenas, lo que podría corresponder a una vista de la muralla en perspectiva, hasta quedar truncadas por lo que podemos interpretar como otra torre de menores dimensiones. Detrás de la torre central se pueden ver dos líneas oblicuas con las mismas almenas triangulares, lo que podría estar indicando la presencia de otra muralla en un segundo plano.

Estas deducciones que tienen evidentemente un alto grado de subjetividad, no evitan 
que el conjunto sí pueda ser considerado como una edificación fortificada. El concepto del dibujante no es algo aleatorio. Existen paralelos de la misma época que definen la vista subjetiva que en aquellos momentos se tenía a la hora de representar estos motivos con trazos simples pero suficientemente significativos. Así, en el castillo de los Calatravos de Alcañiz, en una de las columnas del mirador de la Torre del Homenaje, una imagen muy similar de un probable castillo o ciudad fortificada cuenta con "almenas en punta de saeta o en punta de diamante" y esa división poligonal de la fachada (A. Casanovas y J. Rovira, 2002:24-25). Similares características presentan unos grafitos de torres fortificadas hallados en la Torre del Trovador del palacio de la Aljafería, Zaragoza (J.I. Royo y F. Gómez, 2002:72-73). También guarda gran similitud con las esquematizaciones conceptuales de los castillos acuñados en las monedas de Castilla y León a partir del siglo XIII, en las que los merlones son siempre triangulares y las fachadas esquemáticas.

Si bien lo representado puede ser más conceptual que real, cabe la posibilidad, dada la situación de la vivienda donde se realizó, que se dibujara la vista hacia la puerta de Toledo y la muralla inmediata situada a escasísimos metros al noreste, al otro lado del barranco de las Pozas. Las dos torres situadas en primer plano y vistas de perfil podrían ser las que flanqueaban la puerta de Toledo. Y el muro almenado con un posible torreón situado junto a esta representación de la puerta de Toledo sería el conocido giro de la muralla hacia la puerta de Terrer, bordeando el barranco de las Pozas.

Finalmente, el otro muro situado en segundo plano podría ser perfectamente la muralla interior que separaba la judería del sector cristiano de la ciudad.

Nos encontraríamos ante la primera vista panorámica conocida de Calatayud, muy anterior al grabado titulado Vista oriental de la ciudad de Calatayud publicado en el segundo tomo del Atlante Español (1779). En él la puerta de Toledo, también llamada de Matadores o del Matador tras la guerra con Castilla, aparece flanqueada por dos voluminosos torreones, uno de los cuales al parecer "se le llamó el castellexo, tal vez por su apariencia de castillo" ${ }^{10}$.

\section{Las lámparas de la fiesta de Januká}

La janukía es una lámpara ritual judía de tipo doméstico que se utiliza durante la festividad de Januká. La fiesta, que se prolonga durante ocho días, conmemora la purificación del Templo de Jerusalén en el año 165 a.C. por Judas Macabeo. La lámpara ha de colocarse en un lugar visible junto a la puerta de la vivienda. La janukía cuenta con ocho pequeñas lámparas y una novena o samás, de mayores proporciones, de la que se toma la llama para encender los restantes. Después de la puesta del sol se enciende cada noche una lámpara, hasta que en la octava noche aparecen todas iluminadas.

Teniendo en cuenta que las condiciones materiales de vida de las comunidades cristiana, musulmana y judía en este período no permiten distinguir a cada una por el uso de diferentes cerámicas (M. Beltrán y J.A. Paz, 2002:349), pues todas utilizan las mismas producciones, sólo un ítem particular y exclusivo de alguna de ellas puede hacerlo. Únicamente la comunidad judía hace uso de estas lámparas ceremoniales o janukías, por lo que localizar este elemento entre el ajuar cerámico de una vivienda permite determinar que se trata de un hogar judío.

Cuatro son los ejemplares de janukías hallados. Pertenecen a dos tipos muy similares compuestos por pequeños candiles cerámicos de pellizco, alineados unos junto a otros y colocados sobre un soporte rectangular y macizo de caras generalmente planas. Las

10 A. López, 2003:73-74. Este autor hace referencia a un grabado titulado Vista oriental de la ciudad de Calatayud y conservado en el ayuntamiento de Calatayud, que fecha una vez en el siglo XV y otra a finales del XVI. Sin duda se trata del conocido grabado así titulado, obra de Juan Fernando Palomino y publicado en el segundo tomo del Atlante Español (B. ESPINALT, 1779: Estampa 11). 
únicas diferencias estriban en el acabado vidriado o esmaltado, y en este segundo caso los candiles poseen pie.

Janukía no 1 (fig. 10). Un par de fragmentos que conservan cuatro pequeños candiles de pellizco colocados directamente sobre un soporte rectangular y macizo de caras planas. El conjunto está cubierto parcialmente con un barniz vidriado melado.

Janukía no 2 (fig. 11, 2). La pieza sólo conserva uno de los candiles de pellizco, en este caso con pie, sobre el soporte rectangular y macizo de caras planas. La superficie se halla esmaltada en blanco y decorada en verde-manganeso con motivos geométricos lineales. A ambos lados del pico de la cazoleta se representan motivos oculados, como es típico en las producciones turolenses, "quizás alusivos a los ojos de Dios, Señor y Luz del Universo" (M.I. Álvaro, 2002b:85 y 105) ${ }^{11}$.

Janukía no 3 (fig. 11, 1). Pieza idéntica a la anterior, pero en este caso sólo se conserva el soporte rectangular y macizo de caras planas con parte del pie de un candil y la impronta de otros dos.

Janukía no 4 (fig. 11, 3). Fragmento de lámpara con un candil de pellizco colocado directamente sobre un soporte rectangular y macizo de caras trapezoidales. Cubierto con un vidriado de color melado-verdoso.

Como ya ha sido dicho, el contexto arqueológico de estos hallazgos es diferente. Las dos primeras janukías aparecieron en sendas estancias, en las unidades de incendio y destrucción que las rellenaban. Por lo tanto su cronología no ofrece ninguna duda, tiene que ser anterior a la destrucción sufrida en el verano de 1362. Las dos últimas se encontraron en el basurero, datado entre los siglos XIV y $X V$, que cubre las estructuras de la judería. Sin embargo, dadas sus características formales, la janukía no 3 presentaría la misma cronología que las anteriores.

Las piezas comunes y vidriadas son posiblemente producciones locales ${ }^{12}$, mientras que las esmaltadas y decoradas en verdemanganeso son obra de los alfares de Teruel. Podemos citar entre sus escasos paralelos los conocidos hallazgos procedentes de la judería de Teruel. En las excavaciones realizadas entre 1977-1979 en la plaza de la Judería y en un solar próximo al Torreón de Ambeles, se encontraron restos de tres janukías que su excavadora dató entre los siglos XIII-XIV (P. Atrián, 1981:177), aunque posteriormente se han fechado entre los siglos XIV-XV'13. No obstante, son manifiestas ciertas diferencias formales y decorativas con los ejemplares de Calatayud, como el hecho de estar montadas sobre un soporte cerrado mediante tabiquillos.

Las janukias de Calatayud mantienen mayor semejanza formal con los restos aparecidos en la calle Coso no 196 de Zaragoza (W.AA., 2002c:284-285) ${ }^{14}$. Allí se encontró un fragmento de janukía compuesto por una cazoleta y parte de otra, ambas cubiertas por un barniz estannífero. Se hallaba en un nivel de vertedero datado por las cerámicas de Manises y de Teruel entre fines del siglo XV e inicios del siglo XVI, es decir, poco después de la expulsión en $1492^{15}$. También con los ejemplares recientemente publicados de Tudela, Navarra (J.J. Bienes, 2008:145), algunos al parecer de procedencia turolense. El autor los

\footnotetext{
11 También en el catálogo sobre la cerámica de Teruel se pueden ver varios ejemplos sobre candiles o sobre jarros datados entre finales del siglo XIV y el siglo XV (W.AA. 2002a).

12 Sobre los alfares de Calatayud, consultar la recopilación documental de M.I. Álvaro (2002a: 42-45).

13B. Castillo (2002:191) y W. AA. (2002c:282-283 y 286-287)

14 El solar fue excavado por José Luis Cebolla en 1992.

15 Recientemente ha sido expuesto en el Museo del Teatro Romano de Zaragoza un fragmento de janukía procedente de las excavaciones arqueológicas realizadas en el teatro romano, que fue hallado en el año 2002 (Heraldo de Aragón y El Periódico de Aragón de 13/05/2013). Se trata de un fragmento compuesto por dos candiles en cerámica vidriada, similar a varios ejemplares de Tudela (Navarra), que se ha datado en los siglos XIV-XV. Aunque desconocemos el contexto arqueológico, su importancia estriba en que se hallaron en la zona ocupada por la judería de Zaragoza.
} 
ha fechado por sus características formales entre los siglos XIII-XIV, pero que por desgracia son hallazgos superficiales y descontextualizados $^{16}$. Y finalmente, con algunos de los ejemplares de la forma 2B hallados durante las excavaciones arqueológicas desarrolladas en la judería del castillo de Lorca y que han sido datados en el siglo XV (J. Gallardo y J.A. González, 2009:281-284).

\section{Conclusiones}

Desde el reinado de Jaime I la judería de Calatayud se hallaba sometida a la autoridad real. Correspondía al monarca autorizar cualquier ampliación similar a la que presentamos, pero de momento no hemos encontrado fuentes documentales que puedan apoyar nuestra tesis. Sin embargo, sí existen indicios arqueológicos a su favor. En un contexto arqueológico cerrado y bien datado como el que marca la destrucción de estas viviendas, aparecen dos janukías que sin duda alguna formaban parte de la cultura material de los habitantes de al menos esas dos casas.

En esta nuestra primera aproximación, que compara el registro arqueológico obtenido con el fondo documental hasta el momento publicado en la bibliografía consultada, la interpretación arqueológica se enfrenta a ciertas dificultades.

La primera de ellas podría ser su situación extramuros, aunque inmediata al recinto tradicional de la judería. Sin embargo, otras juderías de similar entidad como la de Zaragoza también poseían una aljama cerrada situada intramuros y otra nueva extramuros.

En segundo lugar, su problemática ubicación sobre un espacio antes ocupado por dos necrópolis. La halajá, la tradición legal judía, considera los cementerios como lugares impuros. Por lo tanto, no era posible ni trabajar sus tierras, ni habitarlos con posterioridad. Pero también es cierto que el nivel de observancia de la normativa halájica varía de acuerdo con las distintas comunidades y tendencias del judaísmo. Igualmente, la amortización de un camposanto cristiano para edificar sobre él pudo suponer importantes conflictos, que sólo serían salvados por la autoridad real.

También las discrepancias sobre las posibles ubicaciones del fosar de los judíos y los hallazgos de dos nuevas necrópolis vienen a complicar la interpretación arqueológica. No obstante resulta verosímil la existencia de dos necrópolis judías que se sucedieran en el tiempo. Una primera situada al Sury al pie del cerro de la Peña en época islámica, merced a los hallazgos de inscripciones y a la cronología atribuida a la dedicada a Semuel, hijo de Rabí Selomoh. Tras la conquista cristiana de Calatayud (1120) con sus consecuentes cambios (sociales, urbanísticos, etc.) y el crecimiento de la ciudad, el fosar pudo ser reubicado a mayor distancia, en la falda del cerro referido por $F$. Cantera (1953:363-364), sin que las viviendas por nosotros excavadas llegasen a ocupar el espacio del anterior cementerio judío, situado probablemente algo más al noroeste.

La existencia de dos cementerios judíos también ha sido propuesta por A. López (2009:294), quien plantea el cambio a causa de la destrucción del primitivo fosar durante la Guerra de los dos Pedros. Sin embargo, la intensa ocupación del terreno inmediato a esa primera necrópolis que hemos documentado arqueológicamente desde al menos el siglo XIII con la fundación del Real Convento de San Pedro Mártir y, posteriormente, con una ampliación de la judería en el siglo XIV no documentada por las fuentes históricas, parece indicar que el cambio debe relacionarse

\footnotetext{
16 Para finalizar este somero repaso a las janukías halladas en la región aragonesa y en el valle medio del Ebro, citar que en las excavaciones arqueológicas desarrolladas durante el año 2009 en el solar de la calle Hospital Viejo 11-15 de Logroño, enclavado en la zona donde tradicionalmente se ha situado la judería logroñesa, aparecieron tres fragmentos de janukias vidriadas en verde en un contexto arqueológico de la segunda mitad del siglo XIV. Su tipología guarda más relación con el ejemplar del Museo Arqueológico de Nájera y los fragmentos de janukías de Pamplona y Estella (M. Ramos et al::129-130). Agradecemos la información a los directores de la actuación, Teresa Angulo y Fernando Porres, y a la autora del estudio, Milagros Martínez (2015).
} 
con la conquista cristiana de Calatayud (1120). En esos momentos o poco tiempo después, siempre dentro del siglo XII, los judíos de Calatayud buscarían un lugar más alejado y más acorde a sus tradiciones para establecer su nuevo cementerio.

Por otra parte, ha quedado demostrado arqueológica y documentalmente que el barrio judío se vio afectado físicamente durante la Guerra de los dos Pedros y que parte de sus viviendas fueron arrasadas en el verano de 1362, durante el terrible sitio castellano a Calatayud. Lo mismo se confirma para el vertedero bajomedieval acumulado sobre las viviendas derruidas y que ciega el foso.

Somos conscientes que los resultados de las excavaciones arqueológicas que presentamos pueden arrojar más dudas que respuestas. Pero también es cierto que la capacidad de adaptación de la comunidad judía en cada lugar hace que en nada se diferencien sus casas a las viviendas de las restantes comunidades religiosas o que "la cerámica utilizada por la comunidad judía no presenta diferencias con la usada por otras capas sociales de población" (M. Beltrán y J.A. Paz, 2002:351). En este caso, los hallazgos muebles evidencian un importante poder adquisitivo. El único elemento diferenciador lo constituye la presencia de las jías, las populares lámparas utilizadas en la fiesta de Januká. Parece obvio que ningún cristiano o musulmán del siglo XIV las poseería entre sus enseres domésticos. Esperamos que en un futuro nuevas excavaciones en este sector de la ciudad puedan contribuir a aclarar la situación.

\section{BIBLIOGRAFÍA}

ÁlVARO, M.I., 2002a, Cerámica Aragonesa. Contexto histórico: los artífices, el trabajo y el medio. Vol. I, Zaragoza.

ÁLVARO, M.I., 2002b, Cerámica Aragonesa. La obra cerámica: La cerámica aragonesa desde el siglo XIII al XVII (1610). Vol. II, Zaragoza.

ATRIÁN, P., 1981, "Lámparas de Hanukkah en cerámica popular turolense”. Teruel. № 66. Teruel, pp. 175-180.
BELTRÁN, M. y PAZ, J.A., 2002, "Estado actual de la arqueología judía en Aragón. Balance y perspectivas de futuro". Aragón Sefarad. Estudios. Vol. I, Zaragoza, pp. 341-353.

BIENES, J.J., 2008, "El legado material de las juderías de Tudela". Revista del Centro de Estudios Merindad de Tudela. № 16. Tudela, pp. 127-150.

BLASCO, Asunción, 2003, "Las sinagogas de Aragón: datos de los últimos diez años", en Juderías y sinagogas de la Sefarad medieval. Cuenca, pp. 189-227.

CANTERA, F., 1953, "Cementerios hebreos de España", Sefarad. Vol. 13. Madrid, pp. 362-367.

CASANOVAS, A. y ROVIRA, J., 2002, "Los graffiti medievales y post-medievales del Alcañiz monumental”, Al-Qannis. No 9. Alcañiz, pp. 5-53.

CASANOVAS, J., 2002, "Epigrafía hebraica aragonesa". Aragón Sefarad. Estudios. Vol. I, Zaragoza, pp. 354-369.

CASTILLO, B., 2002, "Las piezas de una vajilla para la celebración de la Pascua”. Memoria de Sefarad. Toledo, pp 181-192.

CEBOLLA, J.L., ROYO, J.I., REY, J., 1997, La arqueología urbana en Calatayud (1979-1997): datos para una síntesis. Zaragoza.

DE LA FUENTE, V., 1880, Historia de la siempre augusta y fidelísima ciudad de Calatayud. Reedición. Zaragoza, 1969.

DIAGO, M., 2007, "La comunidad judía de Calatayud durante el siglo XIV. Introducción al estudio de su estructura social". Sefarad. Vol. 67, Madrid, pp. 327-365.

ESPINALT, B., 1779, Atlante Español o Descripción general geográfica, cronológica e histórica de España por reynosy provincias. Tomo II: Reynos de Aragón y Mallorca. Madrid.

FITA, F., 1888, "Lápidas hebreas de Calatayud". Boletín de la Real Academia de la Historia. Tomo XII. Madrid, pp. 15-20.

GALLARDO, J. y GONZÁLEZ, J.A., 2009, La judería del castillo de Lorca en la Baja Edad Media. Estudio arqueológico. Murcia.

GARCÍA, M.C., 1989, "Ritos funerarios y preparación para bien morir en Calatayud y su comunidad (1492)". Revista de Historia Jerónimo Zurita, № 59-60. Zaragoza, pp. 89-120.

LÓPEZ, A., 2003, La judería de Calatayud. Sus casas, calles y barrios. Zaragoza.

LÓPEZ, A., 2008, Genealogía judía de Calatayud y Sefarad. Zaragoza.

LÓPEZ, A., 2009, Sabiduría judía de Calatayud y Sefarad. Zaragoza.

MARTÍNEZ, Ma.M. 2015, Arqueología en la Villanueva. Los alfares medievales de la calla Hospital Viejo de Logroño. Logroño. 
MOTIS, M.A., 1995, La Judería de Calatayud. Calatayud.

MOTIS, M.A., 2002, "Las comunidades judías en el Aragón medieval". Aragón Sefarad. Estudios. Vol. I, Zaragoza, pp. 23-112.

MOTIS, M.A., 2005, "La minoría confesional judía en la Comunidad de Calatayud", en Comarca de la Comunidad de Calatayud. Zaragoza, pp. 127-136.

MOTIS, M.A. y AINAGA, M.T., 1987, "Patrimonio urbanístico aljamial de la judería de Tarazona (Zaragoza): las sinagogas, la necrópolis y las carnicerías". Revista de Historia Jerónimo Zurita, no 56. Zaragoza, pp. 83-129.

MUÑOZ, I., 2003, “Juderías de realengo y juderías del señorío: la judería de Calatayud”, Juderías y sinagogas de la Sefarad medieval. Cuenca, pp. 159-188.

OLALLA, J.R., 2005, "Las organizaciones religiosas desde la Conquista hasta la Desamortización de Mendizábal”, en Comarca de la Comunidad de Calatayud. Zaragoza, pp. 137-150.

PELÁEZ, J., 2006, Guía de la sinagoga de Córdoba. Málaga.
RAMOS, M.; LABÉ, L.F. y SÁNCHEZ, A.C., 2011, "Arqueología y cultura judaica", en Príncipe de Viana, no 253, VII Congreso General de Historia de Navarra. Vol. I, Pamplona, pp. 121-133.

ROYO, J.I. y GÓMEZ, F., 2002, "Panorama general de los graffiti murales y de los grabados al aire libre medievales y post-medievales en Aragón". Al-Qannis, no 9. Alcañiz, pp. 55-155.

SANMIGUEL, A., 1989, "El posible emplazamiento del núcleo originario de Calatayud", II Encuentro de Estudios Bilbilitanos. Vol. I. Zaragoza, pp. 149-162.

SANMiguel, A., ed., 2006, Iglesia de San Pedro Mártir. Calatayud. 1368-1856. Zaragoza.

W. AA., 2002a, Operis terre turolii. La cerámica bajomedieval en Teruel. Teruel.

W. AA., 2002b, Aragón Sefarad. Estudios. Vol. I, Zaragoza.

W .AA., 2002c, Hebraica Aragonalia. El legado judio en Aragón. Exposición y catálogo. Vol. II, Zaragoza.

ZURITA, J., Anales de Aragón. Edición electrónica. Zaragoza, 2003. 